\title{
Ultrasound evaluation of obstructive uropathy and its hemodynamic responses in southwest Nigeria
}

\author{
I. N. Apoku ${ }^{1}$, 0. 0. Ayoola ${ }^{1}$, A. A. Salako ${ }^{2}$, B. M. Idowu ${ }^{1}$ \\ ${ }^{1}$ Department of Radiology, Obafemi Awolowo University Teaching Hospitals Complex, Ile - Ife, Osun \\ state, SouthWest Nigeria; ${ }^{2}$ Department of Surgery, Obafemi Awolowo University Teaching Hospitals \\ Complex, Ile - Ife, Osun state, SouthWest Nigeria
}

\section{ABSTRACT}

Purpose: To determine the renal arterial hemodynamic changes induced by obstructive uropathy using Doppler ultrasonography.

Materials and Methods: 60 adult subjects with suspected obstructive uropathy and 60 asymptomatic apparently healthy controls with normal renal ultrasound features were evaluated.

B-mode sonography of the kidneys and spectral Doppler examination of the renal interlobar arteries of all the participants were performed. The mean resistive indices (mRI) of both interlobar arteries were obtained and compared to that of the controls. The mRI of bilaterally obstructed kidneys were also compared with the mRI of unilaterally obstructed kidneys.

Results: The mRI of the right and left kidneys of subjects were $0.72 \pm 0.04$ and $0.69 \pm 0.06$ while those of the controls were $0.64 \pm 0.04$ and $0.63 \pm 0.03$ respectively. The mRI for the grades of caliectasis increased from grade I $(0.72 \pm 0.03)$ to grade II $(0.73 \pm 0.03)$ and grade III $(0.73 \pm 0.02)$ but fell within the most severe levels of obstruction $(0.69 \pm 0.07)$. There was no statistically significant relationship between the grades of caliectasis and unilateral or bilateral obstruction for both kidneys. The results show a sensitivity and specificity of $86.7 \%$ and $90 \%$ respectively when $\mathrm{mRI} \geq 0.7$ was used to determine presence of obstruction.

Conclusion: Renal duplex sonography is highly sensitive and specific for diagnosis of obstructive uropathy. Increased resistive index of the obstructed kidney may be a useful diagnostic tool in situations where intravenous urography cannot be done or is contraindicated.

\section{ARTICLE INFO}

\section{Key words:}

Urologic Diseases; Renal Artery;

Hemodynamics;

Ultrasonography

Int Braz J Urol. 2015; 41: 556-61

Submitted for publication:

April 20, 2014

Accepted after revision:

September 28, 2014

\section{INTRODUCTION}

Obstructive uropathy is a commonly encountered problem in clinical practice. It refers to structural impedance to the flow of urine anywhere along the urinary tract leading to pelvicalyceal dilatation. Renal parenchymal damage resulting from obstructive uropathy is termed "obstructive nephropathy" (1). Obstructive uropathy is often secondary to anatomical pathologies of the uri- nary tract or the genital system. Obstructive uropathy is a known predisposing factor to urinary tract infection, urolithiasis and post-renal renal failure (2). Prompt and accurate diagnosis is crucial to salvaging the affected kidney. The purpose of this study is to assess the renal arterial hemodynamic changes in obstructive uropathy using duplex sonography, and to evaluate the ability of this modality to differentiate obstructed from non-obstructed kidneys. 


\section{MATERIALS AND METHODS}

This prospective, non-randomized, case-control study was carried out in a tropical university teaching hospital from July, 2011 to June, 2012. Approval for the study was obtained from the Ethics and Research Committee of the hospital. Verbal informed consent was obtained from all participants. Sixty adults aged 18 years and above, referred for ultrasonography with symptoms of obstructive uropathy along with 60 age-and sex-matched apparently healthy control subjects were recruited consecutively by the urologist and referred to the sonologist who was blinded to the clinical status of the subjects to minimize bias. The sonologist who carried out the examination was a third year resident at the Radiology department of the institution while the urologist had been practicing as a specialist for 15 years. All subjects had no clinical symptoms and signs, or sonographic features of urinary tract infection. Any participant with clinical symptoms (dysuria, flank pain), signs (renal angle or suprapubic tenderness), or sonographic features (thickened urinary bladder wall, urine containing mobile low-level internal echoes) suggestive of urinary tract infection were excluded from the study. Pregnant women, sickle cell disease patients, diabetic patients, subjects with renal artery stenosis, smokers, hypertensive patients, subjects with congenital renal anomalies, and subjects with elevated urea and creatinine values were excluded from the study. Their age, sex, symptom duration and prospective diagnosis were documented. Subjects who presented as emergency were examined immediately while the others were examined after at least eight hours fasting to reduce intra-abdominal gas and enhance visualization of the renal arteries.

Renal sonography was done in both supine and prone positions using $3.5-5 \mathrm{MHz}$ transducer of MINDRAY ${ }^{\circledast}$ Real time Ultrasound Machine: Model DC-6 (Shenzhen Mindray Bio-medical Electronics, Nanshan, Shenzhen, China). Both kidneys of each subject were initially examined by ultrasonography to rule out congenital anomalies and renal artery stenosis and then to assess for caliectasis. The presence of hydronephrosis was documented for each subject on B-mode and graded as descri- bed by Sehata et al. (3) Thereafter, Doppler studies (color and spectral) of the interlobar arteries was done as previously described (4). The Doppler mode was activated with the Doppler angle adjusted to 60 degrees or less and kept parallel to the vessel wall. The sample gate size used was $1 \mathrm{~mm}$. The interlobar artery resistive indices were recorded for each kidney in subjects and controls by taking three reproducible wave forms from each kidney and averaging them to derive the mRI of the kidney. Finally, a general abdominopelvic ultrasound was done to determine the possible cause of obstruction. Independent samples t test was used to compare the mean age and mRI of subjects and controls. One-way analysis of variance (ANOVA) was used to compare means of variables where there were three or more groups. Chi square test was used to evaluate categorical variables e.g. grades of caliectasis in the proportions of male and female patients. The significance level was set at $\mathrm{p}<0.05$. Data analysis was done using the Statistical Package for Social Sciences (SPSS Inc., Chicago, IL, USA), version 17.0 for Windows.

\section{RESULTS}

There were 120 participants comprising 60 study subjects and 60 controls. The study subjects comprised 27 (45\%) men and 33 (55\%) women, while the controls comprised 32 (53\%) men and 28 (47\%) women; $p=0.465$. The mean age of the study subjects was $48.68 \pm 16.69$ years $\left(\right.$ mean $\left._{ \pm} \mathrm{SD}\right)$ while that of controls was $36.97 \pm 11.19$ years.

Of the 60 subjects, $13.3 \%$ were below 30 years of age, while $23.3 \%, 20 \%$ and $8.3 \%$ were in their $4^{\text {th }}, 5 t^{\text {h }}$ and $6^{\text {th }}$ decades of life respectively. Twenty-one (35\%) subjects were aged 60 years and above. Sixteen (26.7\%) controls were younger than 30 years of age, while 40\%, 16.7\% and 10\% were in their 4th, 5th and 6th decades of life, respectively. Four (6.7\%) controls were aged 60 years and above.

The median symptom duration in subjects was 8 months with a range of 1 week to 5 years.

Twenty (33\%) subjects had uterine fibroid, 16 (27\%) had enlarged prostate, 9 (15\%) had pelvi-ureteric junction obstruction, 7 (11\%) had urinary bladder mass; 4 (7\%) subjects each had ova- 
rian cysts, cervical carcinoma, rectal carcinoma, ureteral stricture and vesico-ureteral obstruction respectively.

Twenty (33.3\%) subjects had unilateral obstruction (either left or right kidney), of which 19 (31.7\%) had only right renal obstruction while 1 had only left renal obstruction. Thirty-three (55\%) subjects had bilateral obstruction while 7 (11.7\%) subjects had no obstruction at all on B-mode sonography.

Based on the assessment of the right kidney, 15 subjects ( 7 men and 8 women) had grade I caliectasis, 22 (12 men and 10 women) had grade II caliectasis, 14 (five men and nine women) had grade III caliectasis while nine (3 men and 6 women) had grade IV caliectasis (Table-1). The $\mathrm{mRI}$ of the right kidney of subjects was $0.72 \pm 0.04$, while that of their left kidney was $0.69 \pm 0.06$ $(p=0.000)$. In the controls, the mRI of the right kidney was $0.64 \pm 0.04$ while that of the left kidney was $0.63 \pm 0.03(\mathrm{p}=0.598)$, (Table-2).

The $\mathrm{mRI}$ of the right kidney in male subjects was $0.72 \pm 0.04$ while that of the female subjects was $0.73 \pm 0.04(\mathrm{p}=0.703)$.

Based on a cut-off mRI value of $>0.70$, the presence of obstructive nephropathy as documented on B-mode ultrasound was predicted with a sensitivity of $86.7 \%$ indicating 52 of the 60 study subjects were identified correctly. The specificity at the same value was $90 \%$ indicating 54 of the 60 controls were predicted correctly as not having obstructive nephropathy as adjudged by absence of caliectasis. Fifty-two (86.7\%) subjects had right renal obstruction $(\mathrm{mRI}>0.70)$ while 8 (33.3\%)

Table 1 - Grades of right renal caliectasis and mRI in subjects.

\begin{tabular}{lccc}
\hline & Caliectasis with normal mRI & Caliectasis with increased mRI & Total \\
\hline Grade I & 1 & 14 & $\mathbf{1 5}$ \\
$(\%)$ & $(6.7)$ & $(93.3)$ & $(100.0)$ \\
Grade II & 1 & 21 & $\mathbf{2 2}$ \\
$(\%)$ & $(4.5)$ & $(95.5)$ & $(100.0)$ \\
Grade III & 0 & 13 & $\mathbf{1 3}$ \\
$(\%)$ & - & $(100.0)$ & $(100.0)$ \\
Grade IV & 5 & 4 & $\mathbf{9}$ \\
$(\%)$ & $(55.6)$ & $(44.4)$ & $(100.0)$ \\
Total & 7 & 52 & $\mathbf{5 9}$ \\
$\%$ & 11.9 & 88.1 & 100.0 \\
\hline
\end{tabular}

Pearson $x^{2}=19.69, \mathrm{df}=3, p=0.000$

Table 2 - Mean Resistive Index (mRI) in the study participants.

\begin{tabular}{lcccc}
\hline & Right kidney & Left kidney & $p$ Value & Note on analysis \\
\hline Subjects, $n=60$ & $0.72 \pm 0.04$ & $0.69 \pm 0.06$ & 0.000 & paired $t$ test, $r=0.4 ; p=0.000$ \\
Controls, $n=60$ & $0.64 \pm 0.04$ & $0.63 \pm 0.03$ & 0.598 & paired $t$ test, $r=0.8 ; p=0.000$ \\
\hline
\end{tabular}


Table 3 - One way ANOVA for right renal mean resistive index by severity of obstruction.

\begin{tabular}{|c|c|c|c|c|c|}
\hline & \multirow[t]{2}{*}{ N } & \multirow[t]{2}{*}{ Mean mRI } & \multirow[t]{2}{*}{ Std. Deviation } & \multicolumn{2}{|c|}{ 95\% Confidence Interval } \\
\hline & & & & Lower Bound & Upper Bound \\
\hline Grade I & 15 & 0.7220 & 0.0336 & 0.70 & 0.74 \\
\hline Grade II & 22 & 0.7341 & 0.0314 & 0.72 & 0.75 \\
\hline Grade III & 13 & 0.7346 & 0.0161 & 0.72 & 0.74 \\
\hline Grade IV & 9 & 0.6911 & 0.0683 & 0.64 & 0.74 \\
\hline Total (All subjects) & 59 & 0.7246 & 0.0395 & 0.71 & 0.73 \\
\hline
\end{tabular}

had normal right kidney $(\mathrm{mRI}<0.70)$. Thirty-four subjects (56\%) had left renal obstruction while 26 (43.3\%) had normal left kidneys.

Analysis of the relationship between grades of caliectasis and mRI of the right kidney showed that in grade I, 1 subject had normal mRI while 14 subjects had increased mRI. In grade II, 1 subject had normal mRI while 21 subjects had increased mRI. All the subjects in grade III had increased $\mathrm{mRI}$. In grade IV, 5 subjects had normal $\mathrm{mRI}$ while 4 had increased $\mathrm{mRI}$. The $\mathrm{mRI}$ by grades of obstruction increased steeply from grade I to III but fell rapidly with the most severe level of obstruction (Table-3). This change was statistically significant $(p=0.030)$. In other words, renal $\mathrm{mRI}$ rose with increasing severity of obstruction up to certain level above which it was less remarkable (Figure-1).

When the grades of caliectasis in unilateral and bilateral obstruction were compared, there were no statistically significant differences in the proportion of subjects with unilateral or bilateral obstruction across each grade of caliectasis $(\mathrm{p}=0.798)$.

Comparison of right renal mRI of the unilaterally and bilaterally obstructed right kidney showed no significant difference between the two groups $(p=0.171)$.

One way ANOVA comparing right and left kidney mRI values in cases of bilateral obstructive nephropathy across the grades of caliectasis showed that there was no significant difference

Figure 1 - Graph of mean resistive index (mRI) versus degree of caliectasis.

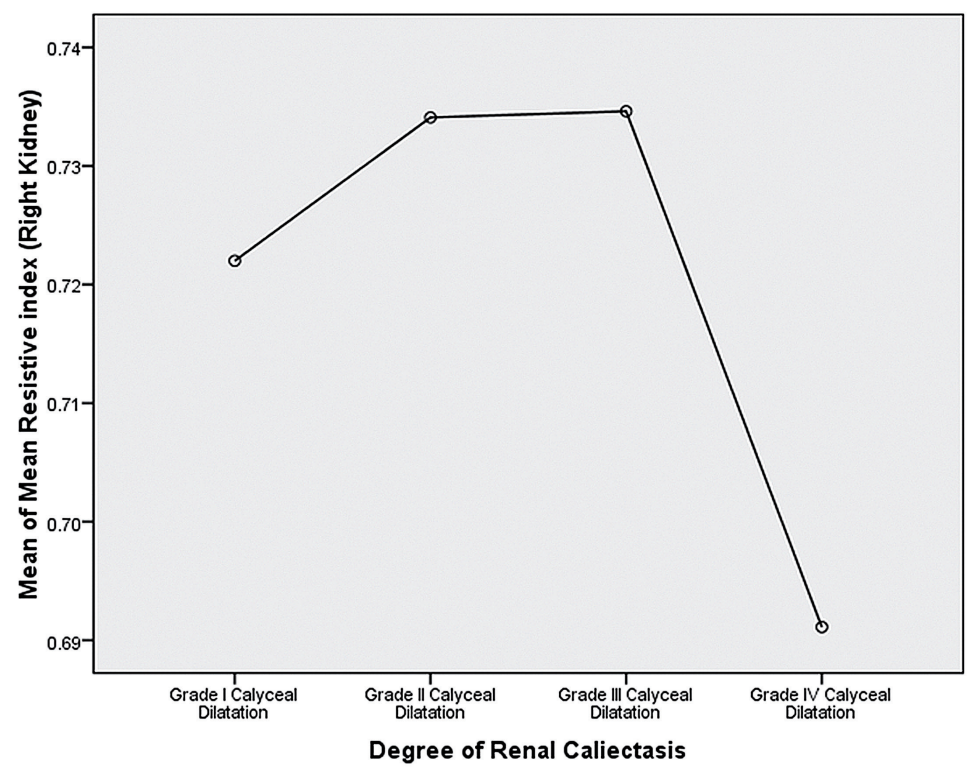


in the $m R I$ values $(p=0.270$ for the right kidney, and 0.480 for the left kidney). There was a moderate positive correlation between the age of study subjects and right renal mRI ( $r=0.4, p=0.006)$. This correlation was also found with the right mRI of the controls $(p=0.000)$. This means that the right renal mRI increased with age in both subjects and controls.

\section{DISCUSSION}

Ultrasonography is cheap, readily available, and also easily identifies the cause of obstructive uropathy. In this study, uterine fibroid was the commonest cause of obstructive uropathy in women while enlarged prostate was the commonest cause in men. This is similar to the findings by Soyebi et al. (5).

This study showed that most study subjects had raised right renal mRI, which may indicate the presence of obstructive uropathy. This was supported by the accompanying calyceal dilatation on grey-scale examination. With urinary obstruction, there is elevation of the pressure within the intrarenal collecting system. This can induce reduction in renal blood flow as a result of increased renovascular resistance. An increase in intra-renal vascular resistance diminishes diastolic blood flow velocity in intrarenal arteries and subsequently, the RI is increased (6).

The subjects had significantly higher right and left renal mRI than the controls $(p=0.000)$.

This means that renal artery hemodynamics change in response to urinary tract obstruction.

Therefore, intra-renal duplex Doppler sonography can provide physiologic information reflecting the renal hemodynamic status by means of the RI (7).

Our sensitivity and specificity using the renal mRI cut-off of 0.70 in the diagnosis of obstruction were $86.7 \%$ and 90\% respectively. This is close to what Platt and his coworkers (8) reported. They had a sensitivity of $92 \%$ and a specificity of $88 \%$ and an overall accuracy of 90\% in diagnosing the presence or absence of obstruction in an adult population. Gottlieb and colleagues (9) also reported a sensitivity of $100 \%$ in a smaller group of adult sub- jects. However, a similar study carried out by Chen and coworkers (10) reported a low sensitivity of 53\%. The discordance in results could be due to the differences in the degrees of urinary tract obstruction and the potential vasodilatory effects of non-steroidal medications typically used for the treatment of pain associated with obstructive uropathy $(11,12)$.

This study also showed that the mRI by grades of obstruction increased steeply from grade I to grade III but fell rapidly with the most severe levels of obstruction. This observation was also reported by Platt et al. (13) where a markedly hydronephrotic kidney did not show an increase in $\mathrm{RI}$ (i.e. $\mathrm{RI}<0.70$ ) despite the presence of what was thought to be obvious severe obstruction. This lack of response is believed to be caused by a marked decrease in absolute blood flow in chronically high grade obstruction (grade IV), and decreased filtration pressure produced by minimally functioning renal cortex or elevated compliance in a capaciously dilated collecting system (14). Rawashdesh et al. (15) also observed that in chronic renal obstruction with marked parenchymal loss, the RI does not change. This was attributed to the probable absence of vasoconstriction at that stage.

\section{CONCLUSIONS}

Mean resistive index (mRI) effectively demonstrates the hemodynamic changes in the renal artery and values $\geq 0.70$ are highly sensitive and specific for identifying an obstructed kidney. Therefore, it may be a very useful tool in patients in whom excretory urography cannot be done or is contraindicated. A limitation of this study is that no other investigative modality was used to corroborate the diagnosis or exclusion of obstructive uropathy in the participants.

\section{ABBREVIATIONS}

mrI $=$ Mean Resistive Index/Indices

\section{CONFLICT OF INTEREST}

None declared. 


\section{REFERENCES}

1. Walsh PC, Retnik AB, Vaughan ED, Wein AJ. Pathophysiology of urinary tract obstruction. In: Campbell's Urology. 7th Ed. Philadelphia: WB Saunders. 1998; pp. 343-60.

2. Klahr S. Obstructive nephropathy; pathophysiology and management. In: Schrier RW (Ed). Renal electrolyte disorder $5^{\text {th }}$ Ed. Philadelphia: Lippincott-Raven. 1997; pp. 554-89.

3. Sehata AA, Azmy TM, El Beblawy MA, Hassn A, Motawe M. Duplex sonography in obstructive Uropathy. Suez Canal Univ Med J. 2003; 6: 277-90.

4. Norris CS, Pfeiffer JS, Rittgers SE, Barnes RW. Noninvasive evaluation of renal artery stenosis and renovascular resistance. Experimental and clinical studies. J Vasc Surg. 1984;1:192-201.

5. Soyebi K.0, Awosanya G.0.G. Causes of obstructive uropathy at the Lagos University Teaching. Niger Q J Hosp Medicine.1996;6:173-7.

6. Klahr S, Pukerson ML. The pathophysiology of obstructive nephropathy: the role of vasoactive compounds in the hemodynamic and structural abnormalities of the obstructed kidney. Am J Kidney Dis. 1994;23:219-23.

7. Karadeniz T, Topsakal M, Eksioğlu A, Ariman A, Basak D. Renal hemodynamics in patients with obstructive uropathy evaluated by color Doppler sonography. Eur Urol. 1996;29:298-301.

8. Platt JF, Rubin JM, Ellis JH. Distinction between obstructive and nonobstructive pyelocaliectasis with duplex Doppler sonography. AJR Am J Roentgenol. 1989;153:997-1000.

9. Gottlieb RH, Luhmann K 4th, Oates RP. Duplex ultrasound evaluation of normal native kidneys and native kidneys with urinary tract obstruction. J Ultrasound Med. 1989;8:609-11.
10. Chen JH, Pu YS, Liu SP, Chiu TY. Renal hemodynamics in patients with obstructive uropathy evaluated by duplex Doppler sonography. J Urol. 1993;150:18-21.

11. Sjödin JG. Clinical experience of indomethacin in pain from ureteral stone. Scand J Urol Nephrol Suppl. 1983;75:35-6.

12. Kmetec A, Peskar-Babnik D, Buturovic-Ponikvar J. Timedependent changes of resistive index in acute renal obstruction during nonsteroidal drug administration. BJU Int. 2002;89:847-50.

13. Patti G, Menghini ML, Todini AR, Marrocco G, Calisti A. The role of the renal resistive index ratio in diagnosing obstruction and in the follow-up of children with unilateral hydronephrosis. BJU Int. 2000;85:308-12.

14. Kapoor R, Saha MM, Mandal AK. Antenatal sonographic detection of Wolffian duct cyst. J Clin Ultrasound. 1989;17:515-7.

15. Rawashdeh YF, Djurhuus JC, Mortensen J, Hørlyck A, Frokiaer $J$. The intrarenal resistive index as a pathophysiological marker of obstructive uropathy. J Urol. 2001;165:1397-404.

\section{Correspondence address:}

B. Michael Idowu, MD

Department of Radiology

Obafemi Awolowo University Teaching Hospitals Complex Ile - Ife, Osun state, South West Nigeria

Telephone: +23 480 32-164-229

E-mail: ibmcontacts@gmail.com 